\title{
Studies of the Relationship between Allergen-Specific IgE Antibodies and Skin Test Reactivity in Patients with Asthma in Kuwait
}

\author{
M.E. Khadadaha B.O. Onadeko ${ }^{a}$ C.I. Ezeamuzie ${ }^{c}$ R. Maroof ${ }^{b}$ \\ H.S. Mustafa ${ }^{a}$ T.N. Sugathan ${ }^{d}$ \\ Departments of a Medicine and ${ }^{\mathrm{b}}$ Hematology, ${ }^{\mathrm{c}}$ Immunopharmacology Unit, \\ Department of Pharmacology, Faculty of Medicine, and \\ dStatistics Unit, Department of Community Medicine, Kuwait University, Kuwait
}

\section{Key Words}

Skin prick test - Specific immunoglobulin E . Allergy · Asthma · Cockroach sensitization

\begin{abstract}
Background: Studies have shown that allergens are important sensitizing agents in asthma. The relationship between various allergy markers has not been documented in Kuwait, although asthma is common. This study was therefore designed to investigate this relationship. Method: One hundred and one adult asthmatics were recruited over a 1-year period for this study. After administering a skin prick test (SPT) for common allergens, blood was taken for measuring specific lgE concentrations. Results: Eighty-two percent of the patients had positive SPT reactions to at least one allergen. Chenopodium sensiti-
\end{abstract}

\begin{tabular}{ll}
\hline KARGER & ( ) 2001 S. Karger AG, Basel \\
Fax +4161306 1234 & Ac11-7571/00/0094-0260\$17.50/0 \\
$\begin{array}{l}\text { E-Mail karger@karger.ch } \\
\text { www.karger.com }\end{array}$ & $\begin{array}{l}\text { Accessible online at: } \\
\text { www.karger.com/journals/mpp }\end{array}$
\end{tabular}

zation was the most common, occurring in $47 \%$ of cases. Specific IgE was positive in fewer cases, which showed a positive reaction to SPT with the same allergen, the highest being observed with cockroach, occurring in $76 \%$ of the cases. There was a positive correlation between the wheal diameter of SPT and the concentration of specific $\lg E$ in three of the four allergens tested $(r=0.376$, $p \leq 0.001$ for Bermuda grass; $r=0.255, p \leq$ 0.01 for cockroach, and $r=0.254, p \leq 0.01$ for chenopodium). The sensitivity, specificity and diagnostic accuracy of SPT in the allergens tested were below the reported findings in studies from Western countries. Conclusion: This study revealed that SPT had a better predictive value than specific $\lg \mathrm{E}$, and there was evidence of increasing sensitization to the cockroach allergen in this environment.

Copyright $@ 2001$ S. Karger AG, Basel

\footnotetext{
Dr. M.E. Khadadah

Department of Medicine, Faculty of Medicine, Kuwait University

PO Box 24923, 13110 Safat (Kuwait)

Tel. +9652666 300, Fax +9652666311

E-Mail mousa@hsc.kuniv.edu.kw
} 


\section{Introduction}

Immunoglobulin E (IgE)-mediated allergy is a major feature of asthma in young patients $[1,2]$. Diagnosis of an allergic disorder is largely based on medical history, which can be confirmed by means of measurement of antigen-specific IgE levels or skin tests [3, 4]. In tropical settings where the prevalence of intestinal helminths is high, serum total IgE levels appear to be much higher than in subtropical countries, and this might present a problem in the interpretation of total IgE levels [5]. Epidemiological studies have shown a relationship between certain respiratory symptoms and distinct patterns of various allergy parameters $[1,6,7]$. These findings may not, however, be applicable to the clinical situation. The value of skin tests and allergen-specific $\mathrm{IgE}$ for predicting symptomatic allergy in patients has been evaluated in some studies in the Western hemisphere [3, 8-10]. However, to our knowledge, no such study has emanated from this region. Indirect evidence based mainly on the results of skin tests suggests that there are differences in the prevalence of atopy from one area to another [11].

Asthma is the most common respiratory disease in the Middle East. Patients are routinely treated according to internationally accepted guidelines. Neither skin test nor serum $\operatorname{IgE}$ (total or allergen-specific) are used in the routine evaluation of patients with asthma in Kuwait. A study of this nature would provide baseline data, which can be used to determine if these allergic parameters are beneficial and relevant to this region in the assessment and monitoring of patients with asthma.

This study has therefore been designed to assess the relationship between skin test reactivity and allergen-specific IgE for common allergens in an environment of low humidity and hot climate with a temperature exceeding $35^{\circ} \mathrm{C}$ for the greater part of the year. It is also being investigated if these markers of atopy are of diagnostic value in asthma.

\section{Patients and Methods}

This study was conducted at the Chest Clinic of Mubarak Hospital, Kuwait (Kuwait University Teaching Hospital) in collaboration with the Immunopharmacology Laboratory of the Faculty of Medicine, Kuwait University between 1998 and 1999. Patients were adults between 15 and 67 years who were diagnosed as suffering from bronchial asthma using the criteria of the National Heart, Lung and Blood Institute [12]. Some of the patients were on a maintenance dose of salbutamol inhaler and inhaled beclomethasone, but no patient had been on oral corticosteroids for the last 12 months. Patients were randomly selected, and the majority were Kuwaitis. All patients were nonsmokers. Ex-smokers were not included in the study.

A comprehensive history, using a specially prepared protocol, was taken from the patients. This included a history of cough, with or without sputum, shortness of breath, chest tightness, wheezing, duration of symptoms, frequency of exacerbations, history of exposure to the allergen and other irritants, and a previous history of asthma and other chest diseases. Family, socioeconomic and occupational history was taken, while a history of previous and current drug therapy was taken as well. All patients had physical examinations.

Patients with a history and findings suggestive of cardiovascular, renal or hepatic diseases were excluded from the study. Similarly, patients who had been exposed to prednisolone in the last 12 months were also excluded.

All patients gave informed consent. The study was approved by the Ethical Committee of the Faculty of Medicine, Kuwait University, Kuwait.

\section{Blood Samples}

Seven milliliters of blood was obtained from each patient on presentation, using a vacutainer, and drawn into vacutubes (vacutainers-SST tubes, Becton, Dickinson, Bedford, N.J., USA). The specimen was allowed to clot at room temperature for $60-120 \mathrm{~min}$. The specimen was centrifuged for $5 \mathrm{~min}$ at $600 \mathrm{~g}$. Serum was collected and stored at $-70^{\circ} \mathrm{C}$ until assay of specific IgE and total IgE.

Skin Testing

Allergen skin tests were carried out according to the prick technique [13], using eight allergens found to be 
common in this geographical area. The allergens applied were Dermatophagoides pteronyssinus (house dust mite, HDM), cockroach, Bermuda grass, chenopodium, egg white, shrimp, peanut and Aspergillus fumigatus. A negative diluent control, $50 \%$ glycerine solution, and a positive control, histamine $1 \mathrm{mg} / \mathrm{ml}$, were included in each series of tests. Twenty minutes after the tests were performed, the results was taken. A wheal of at least $3 \mathrm{~mm}$ in diameter after subtraction of the diameter size of the wheal of the negative control was taken as a positive reaction.

Table 1. Positive SPT encountered in different allergen extracts

\begin{tabular}{lll}
\hline $\begin{array}{l}\text { SPT positive } \\
(\mathrm{n}=82)\end{array}$ & $\begin{array}{l}\text { Patients with } \\
\text { positive SPT of total } \\
\text { population }\end{array}$ \\
\hline Chenopodium (goosefoot) & 47 & 46.5 \\
Mold mix & 30 & 29.7 \\
D. pteronyssinus (HDM) & 28 & 28.7 \\
Bermuda grass & 27 & 26.7 \\
Cockroach & 25 & 24.7 \\
Peanuts & 23 & 22.7 \\
Shrimps & 15 & 14.85 \\
Egg white & 12 & 11.88 \\
\hline
\end{tabular}

IgE Assay

The Pharmacia CAP-FEIA R test system comprising the CAP-RAST test was used for the allergen-specific IgE. Allergen-specific IgE was determined for the following allergens: D. pteronyssinus, pollen of Bermuda grass, goosefoot (Chenopodium album), cockroach (Blatella germanica), egg white, peanut and shrimp. This test system is a fluoroenzymatic modification of the conventional RAST test. The intensity of the resulting color was measured in a spectrometer. Results were expressed in kilounits per liter. These were obtained by reference to a standard curve derived with serial dilutions of human $\mathrm{IgE}$ which was calibrated against the World Health Organization standard for IgE (standard WHO 75/602). One kilounit per liter corresponds to $2.4 \mathrm{ng}$ of IgE per liter. A value greater than $0.35 \mathrm{kU} / 1$ is defined as a positive CAP system result. The degree of positivity was classified into categories 0-6 according to Pharmacia CAP-RAST criteria.

\section{Statistical Analysis}

The Spearman rank correlation coefficient was estimated to quantify the correlation between skin test diameter size and serum concentration of allergen-specific IgE. The skin test sensitivity, specificity and diagnostic accuracy were calculated using the method advocated by Kirkwood [14].

Table 2. Degree of positive reaction to specific $\mathrm{IgE}$ in the four most common allergens isolated

\begin{tabular}{|c|c|c|c|c|c|}
\hline \multicolumn{2}{|c|}{$\begin{array}{l}\text { Category of specific IgE positivity } \\
\mathrm{kU} / 1 \text { (class } 0-6 \text { ) }\end{array}$} & \multirow{2}{*}{$\begin{array}{l}\text { Cheno- } \\
\text { podium } \\
\mathrm{n}\end{array}$} & \multirow{2}{*}{$\begin{array}{l}\text { Cock- } \\
\text { roach } \\
n\end{array}$} & \multirow{2}{*}{$\begin{array}{l}\text { Bermuda } \\
\text { grass } \\
\mathrm{n}\end{array}$} & \multirow{2}{*}{$\begin{array}{l}\mathrm{HDM} \\
\mathrm{n} \\
90\end{array}$} \\
\hline$(<0.35)$ & 0 negative & & & & \\
\hline$(0.35-0.7)$ & 1 & 6 & 2 & 2 & 1 \\
\hline$(0.7-3.5)$ & 2 & 10 & 12 & 8 & 6 \\
\hline$(3.5-17.5)$ & 3 & 10 & 5 & 8 & 3 \\
\hline$(17.5-50)$ & 4 & - & - & - & - \\
\hline$(50-100)$ & 5 & - & - & 1 & 1 \\
\hline$(>100)$ & 6 & - & - & - & - \\
\hline \multicolumn{2}{|c|}{ Total number of positive cases } & 26 & 19 & 19 & 11 \\
\hline
\end{tabular}

$\mathrm{n}=$ Number of cases. 


\section{Results}

One hundred and one adult patients were recruited for the study. There were 61 males and 40 females, giving a ratio of 3:2. Their ages ranged from 15 to 67 years with a mean of $30.34 \pm 14.08$ and a median of 29 . The duration of asthma varied from 2 to 18 years. The skin prick test (SPT) was positive for at least one allergen in $82(81 \%)$ of cases.

Table 1 shows the skin test results in the patients. Goosefoot (C. album) was the most frequently encountered allergen extract, being positive in $46 \%$ of cases, followed by mold mix and HDM (D. pteronyssinus) in 30 and $29 \%$ of cases, respectively. Positive skin test reactivity to cockroach was observed in 25\% of cases. Positive specific IgE according to degree is illustrated in table 2 for the four common allergens in this environment.

Positive skin test reactions were compared with CAP specific IgE positivity in four common allergens found in this environment. While SPT was positive in 47 cases of chenopodium, it was observed that the specific IgE assay was positive in only $26(55 \%)$ of the cases. In the cockroach antigen, 25 of the cases had positive SPT reaction while 19 were positive to specific IgE assay. The lowest positivity of specific IgE was recorded in the case of HDM, where only 11 (39\%) of the 28 cases

Table 3. Number of patients with positive SPT and positive allergen-specific IgE using four common allergens in Kuwait

\begin{tabular}{lll}
\hline Allergen & $\begin{array}{l}\text { SPT } \\
\text { positive }\end{array}$ & $\begin{array}{l}\text { CAP specific } \\
\text { Ig positive }\end{array}$ \\
\hline Chenopodium & 47 & 26 \\
D. pteronyssinus (HDM) & 28 & 11 \\
Bermuda grass & 27 & 19 \\
Cockroach & 25 & 19 \\
\hline
\end{tabular}

Specific IgE and Asthma in Kuwait of positive SPT also had a positive specific $\mathrm{IgE}$ result to HDM. The results are illustrated in table 3.

Table 4 shows the distribution of sensitivity, specificity and diagnostic accuracy of SPT, using the CAP specific IgE as a reference standard. For the four common allergens, the SPT

Table 4. Sensitivity and specificity of SPT using CAP specific IgE for four common allergens

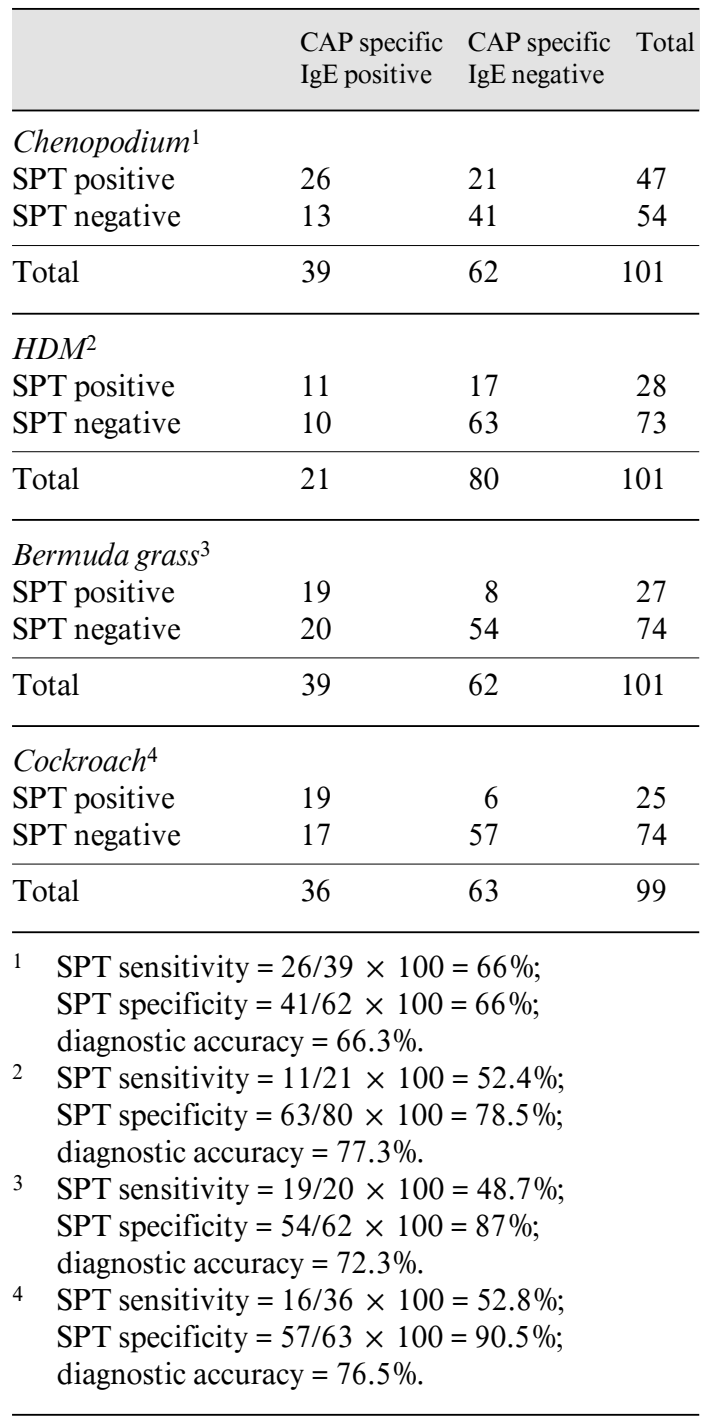

Med Principles Pract 2000;9:260-267 
Table 5. Correlation between SPT wheal diameter and CAP specific IgE concentration (kU/l)

\begin{tabular}{lcccc}
\hline Variable & HDM & $\begin{array}{l}\text { Bermuda } \\
\text { grass }\end{array}$ & $\begin{array}{r}\text { Cockroach } \\
\begin{array}{l}\text { Cheno- } \\
\text { podium }\end{array}\end{array}$ \\
\hline $\begin{array}{l}\text { HDM (D. pteronyssinus) } \\
\begin{array}{l}\text { Bermuda grass } \\
\text { Cockroach }\end{array}\end{array}$ & 0.165 & & & \\
Chenopodium & & $0.376^{* * *}$ & $0.255^{* *}$ & \\
\hline
\end{tabular}

Spearman's correlation coefficient; ${ }^{* *} \mathrm{p} \leq 0.01,{ }^{* * *} \mathrm{p} \leq 0.001$. sensitivity was generally low. It was only in the case of chenopodium that it was above $60 \%$, and that was only $66 \%$. However, SPT specificity was much higher; the highest was observed in Bermuda grass and cockroach with 87 and $90 \%$, respectively. The diagnostic accuracy of SPT was above $70 \%$ in all except that of chenopodium.

The wheal size diameter of SPT was correlated with the concentration of specific IgE for the four allergens. The findings are shown in table 5. There was a positive correlation with Bermuda grass $(r=0.376, p \leq 0.001)$, cockroach $(r=0.255, p \leq 0.01)$, and chenopodium $(\mathrm{r}=0.254, \mathrm{p} \leq 0.01)$. No correlation was observed with HDM.

\section{Discussion}

Allergen-specific $\operatorname{IgE}$ determination is widely used in the diagnosis of IgE-mediated allergic diseases, but the relative merits of in vitro measurement of IgE antibody in comparison to in vivo skin tests are still debated [15].

In this study, allergen sensitivity was high, being found in $81 \%$ of the cases in this environment. A similar finding was recorded for inhalant-allergens among blood donors in an earlier study from the same environment [16]. A high sensitivity had also been observed among the asthma population in Europe and United States of America (USA). Kang et al. [17] recorded a prevalence of $85 \%$ among patients in an inner city study of asthma in Chicago, while Hendrix et al. [18] reported a figure of $88 \%$ in London and Burrows et al. [19] had a figure of $72 \%$ among adults in Tucson, Arizona, USA.

Chenopodium was the most commonly identified allergen among the adult population. This is a weed found to be growing in gardens of houses in the city. HDM the allergen most commonly found in Europe, was the third commonly recognized allergen in this study; this finding being similar to that of Ezeamuzie et al. [20] in their recent study in the same environment. In their study, in which a large number of patients was enrolled, $70 \%$ of their patients gave a positive reaction to chenopodium, while HDM reactivity was only observed in $48 \%$ of cases, being the sixth most common allergen. However, the findings in these two studies were in contrast to those obtained in Europe and USA [21-23] where HDM was the most commonly found allergen. In Indonesia, a tropical country in Asia, HDM predominated among the allergens found after skin testing, the reason probably being the fact that Indonesia has high humidity, high rainfall and moderate temperature compared with Kuwait. HDM is known to thrive in an environment of high 
humidity and moderate temperature [24]. The reason for a low prevalence of HDM in Kuwait may be related to the environmental and geographical condition of Kuwait, where the climate is dry and hot, with low humidity of $15-30 \%$ and very little rainfall.

Cockroach is assuming an increasing importance in allergen sensitivity in Kuwait. Skin reactivity to cockroach was found in $25 \%$ of the cases. In a recent study using a larger sample size, a prevalence as high as $58 \%$ was observed [20] in the same environment. It was observed that cockroach was the most prevalent sensitizing indoor allergen, much more than HDM. A high prevalence of cockroach allergen sensitivity has been reported in several studies in Europe and America, especially among patients from the low socioeconomic class [25-29].

Kang et al. [17], in their study of aeroallergen sensitivity in Chicago, found $45 \%$ of all cases to be sensitive to cockroach, second only to HDM. The asthma population of Chicago is representative of the low socioeconomic class of the inner city. A similar observation was made by Mendoza and Snyder [25] in New York City: cockroach sensitivity was reported in $44 \%$ of the atopic asthma population. Cockroach sensitization has also been reported in Spain [30, 31], and a recent study [32] also reported that cockroach sensitivity was the most important indoor allergen in Madrid [32].

The reason for the increasingly high cockroach reactivity in asthma in Kuwait is not clear, as Kuwait is an oil-rich country with a low population, whereas reports of high prevalence have emanated from the low socioeconomic class of patients in crowded urban areas. It is conceivable that some of the patients included in the study, though of Arab ethnic origin, might have come from the crowded area of the city where the nonindigenous migrant workers also live. Furthermore, although the majority of Kuwaiti patients $(80 \%)$ included in the study come from the upper and middle social classes, it is recognized that in this study virtually all households keep maids and other domestic helpers who are from a low socioeconomic class originating from some Asian countries where studies have shown a high prevalence of cockroach infestation. These helpers interact freely with members of the Kuwaiti household, and they could easily transmit cockroach allergens to them, resulting in sensitization after prolonged exposure.

It was observed from this study that only a proportion of patients with a positive SPT also had a positive CAP specific IgE to the same allergen at the same time. Only 39\% of patients who had positive skin test reactions to HDM also showed positive specific IgE to the same allergen. The corresponding figures for Bermuda grass and cockroach were 70 and $76 \%$, respectively. This finding has demonstrated that the CAP specific IgE test is less sensitive than the skin test, as has previously been reported in similar studies [32-34]. A recent study by Ezeamuzie et al. [35] also confirmed that specific $\operatorname{IgE}$ positivity is much lower than SPT positivity. They also found that in the normal Kuwaiti population the specific IgE positivity is, however, much lower than the asthmatic population, with a figure of $5.8 \%$.

The sensitivity, specificity and diagnostic accuracy of the skin test were examined using CAP specific IgE as a reference standard. The low sensitivity recorded may be due to geographical and sociocultural differences when compared with the results obtained from studies done in Europe, where high sensitivity and specificity were generally recorded [36]. Santoso [37], however, in his own study using the HDM allergen alone, recorded a high sensitivity but a low specificity. 
An interesting correlation between the size of the wheal of the SPT and the concentration of specific IgE in the four common allergens was observed. There was a significant correlation with Bermuda grass, cockroach and chenopodium, while none was obtained with HDM. On the contrary, in the study of Santoso [37] in Indonesia, there was a positive correlation between wheal size and RAST scores to HDM. In that study, HDM was the most prevalent allergen, but in this study, the prevalence of HDM was low. This might have been responsible for the absence of a significant correlation.

\section{Conclusion}

This study has revealed that SPT is the most convenient and cost-effective method for detecting allergen sensitivity. It may, however, be necessary to confirm the positive reaction of SPT with the CAP-RAST system for the evaluation of allergens in patients with allergic asthma. This study has shown the upward trend of cockroach as an allergen of significance in asthma in this environment. Finally, the study has shown that the sensitivity of SPT is higher than that of the CAPRAST system in the four common allergens examined.

\section{Acknowledgment}

This study was supported by a grant from Kuwait University, Research Administration (grant M 039). We acknowledge the assistance of Dr. Susan Thomson and Mrs. Elizabeth Philip of the Immunopharmacology Unit of the Department of Pharmacology, Kuwait University, who were responsible for the specific IgE CAP system assay. We would like to thank Dr. Latha Varma, Chief Technician, Department of Medicine for procuring the IgE kits for the survey. We are grateful to Dr. Nabil Al-Maradni of the Chest Unit, Mubarak Hospital, and Ms. Ajitha Suresh, Scientific Assistant for the Statistical Unit of the Department of Community Medicine for assistance with computation and analysis of the data.

\section{References}

1 Burrows B, Martinez FD, Halonen M, Barbee RA, Cline MG: Association of asthma on the serum IgE levels and skin test reactivity to allergens. N Engl J Med 1989;320:271277.

2 Sporik R, Holgate ST, Platts-Mills TAE, Cogswell JJ: Exposure to house dust mite allergen (Der p I) and the development of asthma in childhood: A prospective study. N Engl J Med 1990;323:502-507.

3 Ferguson AC, Murray AB: Predictive value of skin prick tests and radio allergosorbent tests for clinical allergy to dogs and cats. Can Med Assoc J 1986;134:1365-1368.

4 Van Arsdel PP Jr, Larson EB: Diagnostic tests for patients with suspected allergic disease: Utility and limitations. Ann Intern Med 1989; 110:304-312.
5 Turner KJ, Dowse GK, Stewart GA, Alpers MP: Studies on bronchial hyperreactivity, allergic responsiveness, and asthma in rural and urban children of the highlands of Papua New Guinea. J Allergy Clin Immunol 1986;77:558-566.

6 Mensinga TT, Schouten JP, Rijcken B, Weiss ST, Speizer FE, van der Lende R: The relationship of eosinophilia and positive skin test reactivity to respiratory symptom prevalence in a community-based population study. J Allergy Clin Immunol 1990;86:99-107.

7 Tollerud DJ, O'Connor GT, Sparrow D, Weiss ST: Asthma, hayfever and phlegm production associated with distinct patterns of allergy skin test reactivity, eosinophilia, and serum IgE levels: The normative aging study. Am Rev Respir Dis 1991; 144:776-781.
8 Lopez LR, Noriega Y, Losno R: Immediate skin test reactivity to common aerogens in patients with respiratory allergies: A comparative analysis of allergen-induced skin reaction and their histamine control. J Allergy Clin Immunol 1988;81: 1143-1148.

9 Finnerty JP, Summerell S, Holgate ST: Relationship between skin-prick tests, the multiple allergosorbent test and symptoms of allergic disease. Clin Exp Allergy 1989;19:51-56.

10 Petersson G, Dreborg S, Ingestad R: Clinical history, skin prick test and RAST in the diagnosis of birch and timothy pollinosis. Allergy 1986;41: 398-407. 
11 Vital and Health Statistics: Percutaneous Immediate Hypersensitivity to Eight Allergens. Data from National Health Survey series II. Washington, US Government Printing Office, 1986, No 235.

12 National Education and Prevention Program: Expert Panel Report II. Guidelines for the Diagnosis and Management of Asthma. Bethesda, National Heart, Lung and Blood Institute and National Institute of Health, 1997.

13 Pepys SJ: Skin test in diagnosis; in Gell PG, Coombs RRA, Lachmann PJ (eds): Clinical Aspects of Immunology, ed 3. Oxford, Oxford Scientific Publications, Oxford, 1975, pp 54-80.

14 Kirkwood BR: Essentials of Medical Statistics. Oxford, Blackwell Scientific Publications, 1988, pp 163164.

15 Plebani M, Borghesan F, Faggian D: Clinical efficiency of vitro and in vivo tests for allergic diseases. Ann Allergy Asthma Immunol 1995;74: 23-28.

16 Ezeamuzie CI, Al-Mousawi M, Dashti H, Al-Basher A, Al-Hage M, Al-Ali S: Prevalence of allergic sensitization to inhalant allergens among blood donors in Kuwait, a desert country. Allergy 1997;52:11941200.

17 Kang BC, Johnson J, Veres-Thorner $\mathrm{C}$ : Atopic profile of inner-city asthma with a comparative analysis on the cockroach-sensitive and ragweed-sensitive subgroups. J Allergy Clin Immunol 1993;92:802-811.

18 Hendrix DJ, Davies FJ, D-Souza MF, Pepys J: An analysis of skin prick test reactions in 656 asthmatic patients. Thorax 1975;30:2-8.

19 Burrows B, Lobowitz MD, Barbee RA: Respiratory disorders and allergy skin test reactions. Ann Intern Med 1976;84:134-139.
20 Ezeamuzie CI, Thomson MS, Al-Ali S, Dowaisan A, Khan M: Asthma in the desert. Allergy 2000;55:157162.

21 Brand PL, Kerstjens HA, Jansen HM, Kauffman HF, deMonchy JG: Interpretation of skin tests to house dust mite and relationship to other allergy parameters in patients with asthma and chronic obstructive pulmonary disease. J Allergy Clin Immunol 1993;91:560-570.

22 Kang BC: Cockroach allergy. Clin Rev Allergy 1990;8:87-98.

23 Platt-Mills TAE, de Weck AL: Dust mite allergens and asthma, a worldwide problem. J Allergy Clin Immunol 1989;83:415-427.

24 Arlan LG: Biology and ecology of house dust mites: Dermatophagoides Spp. and Euroglyphus Spp. Immunol Allergy Clin North Am 1989;9:339-356.

25 Mendoza J, Snyder RD: Cockroach sensitivity in children with bronchial asthma. Ann Allergy 1970;28: 159-163.

26 Bernton HS, McMahon TF, Brown $\mathrm{H}$ : Cockroach asthma. $\mathrm{Br} \mathrm{J}$ Dis Chest 1972;66:61-66.

27 Kang B: Study on cockroach antigen as a probable causative agent in bronchial asthma. J Allergy Clin Immunol 1976;58:357-365.

28 Kang B, Vellody D, Homburger H, Yuninger JW: Cockroach cause of allergic asthma. J Allergy Clin Immunol 1979;63:80-86.

29 Kang BC, Wu CW, Johnson J: Characteristics and diagnosis of cockroach-sensitive bronchial asthma. Ann Allergy 1992;68:237-244.
30 Gonzalez P, Vega F, Garcia A: Cockroach skin test reactivity in an urban area (Madrid) (abstract). Allergy 1992;475(suppl):1276.

31 Pola J, Valdivieso R, Zapata C, Moneo L, Duce F, Losasa E: Cockroach hypersensitivity in asthmatic patients. Allergol Immunopathol (Madrid) 1988;16:105-107.

32 Ibanez SJ, Lombardero M, Laso MT, Lehrer S: Allergy to cockroaches in patients with asthma and rhinitis in an urban area (Madrid). Allergy 1996;51:582-586.

33 Bousquet J, Michel FB: In vivo methods for study of allergy; in Middleton E, Reed CE, Ellis EF, Adkinson NF, Yunginger JW, Busse WW (eds): Allergy Principles and Practice. St Louis, Mosby 1993, pp 573-594.

34 Fernandez A, Patino C, FernandezCaldas E, Puerta L, Lockey R, Baena-Cagnani C: Skin test versus RAST to cockroach allergens (abstract). J Allergy Clin Immunol 1994;93:173.

35 Ezeamuzie CI, Al-Ali S, Khan M, Hijazi Z, Dowaisan A, Thomson MS, Georgi J: IgE-mediated sensitization to mould allergens among patients with allergic respiratory diseases in a desert environment. Int Arch Allergy Immunol 2000;121: 300-307.

36 Kong-Ling Kam, Kue-Hsung Hsieh: Comparison of three in vitro assays for serum IgE with skin testing in asthmatic children. Ann Allergy 1994; 73:329-330.

37 Santoso $\mathrm{H}$ : The value of a single skin prick testing for specific IgE Dermatophagoides pteronyssinus to distinguish atopy from non-atopic asthmatic children in the tropics. Asian Pac J Allergy Immunol 1998;16:69_ 74 